\title{
Minorities in Higher Education in the United States: Their Status and Disparities in Student and Faculty Representation in a Midwest Research I University
}

\author{
Shatomi Luster-Edward ${ }^{1} \&$ Barbara N. Martin ${ }^{2}$ \\ ${ }^{1}$ University of Missouri (MU) Extension, Missouri, USA \\ ${ }^{2}$ University of Central Missouri, Missouri, USA \\ Correspondence: Barbara N. Martin, College of Education, University of Central Missouri, Warrensburg, MO., \\ 64093, USA. Tel: 1-660-543-8823. E-mail: bmartin@ucmo.edu
}

Received: November 14, 2018

Accepted: December 2, 2018

Online Published: December 18, 2018

doi:10.5539/hes.v9n1p68

URL: https://doi.org/10.5539/hes.v9n1p68

\begin{abstract}
This paper investigated diversity disparity in high education relating to faculty and the student body. The research identified the perceived leadership behaviors, policies, and procedures determined by minority faculty and students contributing to minority populations disparities within the University. The conclusions suggested higher education leaders should embrace and encourage differences and implement strategies that will adequately support inclusive policies within the higher education system to increase the organizational value of diversity through equitable populations.
\end{abstract}

Keywords: higher education, diversity, change agent and leadership

\section{Introduction}

\subsection{Statement of the Problem}

Diversity and inclusion in educational institutions are ongoing challenges throughout the United States (Phillips, 2016), which affects communities, the private and public sectors, and general interactions and communication amongst individuals (Cottrill, Lopez, \& Hoffman, 2014). Higher education is one of those areas of misrepresentation for people of color through the student body, leadership, faculty, and administration (Brown-Glaude, 2009). Furthermore, higher education policies and articulation agreements are often contributing factors to the lack of diversity within universities (Crownson, Mitchell \& Shipps, 2011). Therefore, the goal of this study was to investigate the perceptions of stakeholders regarding diversity. Specifically, the researchers investigated a Research I University's' leadership behaviors, policies, and procedures to examine if those behaviors and procedures contribute to what it means to create an inclusive diverse environment for students and faculty of color.

\subsection{Significance of the Problem}

Falherty (2015) suggested the present-day disparity of people of color cultivates a fragmented culture that lacks diversity for post-secondary educational institutions. Historically the access to education, more specifically post-secondary education for minority groups, especially African Americans have not been promising (Crowson, Mitchell, \& Shipps, 2011). Further argued by Crowson, et al. is while universities are conduits for student academics, self and professional development, most institutions lack diversity emulating the population of most communities (Crowson, et al., 2011). Thus, conducting this study contributed to the exploration for the need to change policy and procedures that will result in increased diversity for the student and the faculty population in higher education (Creswell, 2009). The purpose of this research study was to investigate the perceived leadership behaviors, policies, and procedures identified by minority faculty and students regarding diversity in a higher education institution, and how they contributed to the lack of diversity within the student and faculty population.

\subsection{Conceptual Framework}

Two theoretical frameworks are the nucleus of this study and are related to underrepresentation of minorities, and related diversity procedures within higher education: cultural competence (Gaetano \& Espana, 2010), and critical theory (Delgado \& Stefancic, 2012). As the research commenced, emphasis compelled further analysis of 
these conceptual frameworks.

Cultural competency revealed the importance of not only understanding and analyzing culture but the validity of cultural submersion (Gooden \& Norman-Major, 2012) in a higher education setting. Cultural competence submersion implies diversity integration that incorporates thought, communication, and action (Gooden \& Norman-Major). Cultural competence further requires individuals and organizations to have a defined set of values and principles, demonstrating behaviors, attitudes, policies, and structures that enable them to work effectively in a cross-cultural manner (Diller \& Moule, 2005). Establishing these cultural attributes and characteristics within an educational setting enhances the value of the organization, the people, and the organizational outcome (Diller \& Moule; Gooden \& Norman-Major, 2012). Moreover, Diller and Moule (2005) implied cultural competencies requires leaders to demonstrate the capacity to value diversity, engage in self-reflection, facilitate the dynamics of diversity effectively, acquire and institutionalize cultural knowledge. The culturally competent leaders should support actions that foster equity of opportunity and services and advocate the above attributes in all aspects of leadership, policymaking, and practice while systematically involving all key stakeholders and communities. (Diller \& Moule, 2005, p. 3)

Likewise, cultural competency is an effective learning tool and when implemented succinctly it evolves individuals and organizations (Gooden \& Norman-Major, 2012). Consequently, the conceptual framework of cultural competency helps illustrate the importance of effective communication, intervention, and outcomes in a multicultural environment (Gallegos, Gallegos \& Tindall, 2008).

Scholars had attempted to understand the reasons as to why the implementation of cultural competency does not occur with fidelity in organizations (Coleman \& Pellitteri, 2013). Cross (1989) emphatically suggested that the disparities for student and faculty of color in a higher education environment results in a cycle of three cultural characteristics that include cultural destructiveness, cultural incapacity, and cultural denial/indifference.

Cultural destructiveness begins with privilege (Coleman \& Pellitteri, 2013) and is demonstrated when a person or organization, alike, consciously uses power to destroy cultures that do not mirror their own. In a privilege environment, there is often a superiority message that is communicate to outside cultures, implying the value of other cultures are diminished and not welcomed. Coleman and Pellitteri (2013) further argued this privilege harms other cultures leading to cultural incapacity.

Cultural incapacity suggests a group subconsciously is simply taking care of their own (Coleman \& Pellitteri, 2013). This results in homogeneousness, since the group is comfortable with maintaining the status quo (Coleman \& Pellitteri, 2013). However, if "the group" is the dominant culture it creates an institutional and systematic bias, in a form of denial and indifference.

Cultural denial/indifference takes the stance of "all people are the same" (Coleman \& Pellitteri, 2013) which results in suppressed culture and differences. Furthermore, there is disregard for the benefits and strengths of difference and culture. It also entails that policies, opportunity, access, and achievements are fair and suggests all an individual should do is pull oneself up by their bootstraps and make it work. This cultural indifference is blatant denial and refutes consideration of privilege and access assumed or given to specified groups (Coleman \& Pellitteri, 2013).

These characteristics of cultural destructiveness, cultural incapacity, and cultural denial/indifference help define the cause for color disparity and misrepresentation within organizations, more specifically higher educational institutions (Coleman \& Pellitteri, 2013). While some of these behaviors are unintentional, it still does not minimize the impact. Coleman and Pelliteri further suggested organizations should eventually gravitated towards cultural pre-competence, transcending into cultural competence and finally to cultural proficiency. Achieved through the suggested cycle of seven (learning, acknowledge, awareness, knowledge, engage and integrate, revise and refine) demonstrated by Gooden and Norman-Major (2012) is cultural proficiency.

The second conceptual framework for this inquiry was critical race theory (CRT) used as an analytical framework to assess inequity in education (Parker \& Villalpando, 2007). Scholars have used CRT as a framework to further examine educational research and practice (Ladson-Billings, 2009). As a result, CRT analyzes the role of race and racism in perpetuating social disparities between dominant and marginalized racial groups (Ladson-Billings). CRT's purpose is to discover what is taken for granted when analyzing race and privilege, as well as the profound patterns of exclusion that exist in American society (Parker \& Villalpando).

There are three basic tenets of CRT (Delgado \& Stefancic, 2012): ordinariness or essentialism, interest convergence, and social construct or intersectionality. Many CRT theorists would agree these tenets are the usual way that society does business (Litowitz, 2009). 
Ordinariness/essentialism, the first featured tenet, describes this notion of acknowledgment or the concept that addressing racism is not possible because it does not exist (Delgado \& Stefancic, 2012). Color-blindness is the premise of this CRT feature, we all should be treated because we are all equal (Delgado \& Stefancic). The rules for everyone should be consistent and only blatant and outwardly, displays of discrimination should render a swift and different action. However, this omits the subtler forms of discrimination, standardized testing, mortgage qualifications, or the misrepresentation of minority faculty/student body remised (Delgado \& Stefancic; Litowitz, 2009).

Convergence or material determinism suggest personal advancement for personal gain (Delgado \& Stefancic, 2012). For white elites or the working class may have little motivation to eradicate racism, unless there is a benefit for self or others involved. Delgado and Stefancic inserted the example of Brown versus the Board of Education. During this trial simultaneously the United States was communing international partnerships and alliances, however, implementation of equal but separate was difficult for the United States to administer when we had significant struggles of our own about discrimination and diversity (Delgado \& Stefancic).

Intersectionality or social construct is the last tenet (Delgado \& Stefancic, 2012; Litowitz, 2009). This tenet suggests a group-think mentality with race viewed as a product of social thought and relation that can be discarded, manipulated, or treated as a societal event when convenient (Delgado \& Stefancic). Specifically, categorized and judged by the color of ones' skin, hair type, physique, and certain physical traits is race. Often in intersectionality, ignored and treated as a stereotypical class is the individual (Delgado \& Stefancic, 2012).

The three tenets: ordinariness/essentialism, concept of interest convergence, and intersectionality/social construct is the backbone of critical race theory (Delgado \& Stefancic, 2012; Hiraldo, 2010). Telling the story as to why treatment of people of color occurs in a particular matter. It also provides an outlet of understanding with the hopes of change (Delgado \& Stefancic).

Recognizing these tenets in higher education will recognize the consequences of the lack of diversity. Therefore, CRT can demonstrate an important role when higher education institutions work toward becoming more diverse and inclusive (Delgado \& Stefancic, 2012). For example, in a predominantly white institution (PWI) simply working toward increasing the number of students of color enrolled, is an insufficient goal, if institutional change is a priority (Bardach, 2012). Examining the campus climate efforts for competence in awareness, conversion, social construct and inclusiveness will help to understand the value for diversity within the student body, staff, faculty, and administrators (Gooden \& Norman-Major, 2012).

In summary, cultural competency and critical race theory provided the appropriate conceptual frameworks in which to explore the problem and examine the research questions. First cultural competence requires individuals and higher education organizations to demonstrate behaviors, attitudes, policies, and structures that enable them to work effectively in a cross-cultural manner (Diller \& Moule, 2005). Next, CRT focused on revealing what is taken for granted when analyzing race and privilege, as well as the profound patterns of exclusion that exist in a higher education institution (Parker \& Villalpando, 2007).

\subsection{Research Design and Research Questions}

In this study, utilized was a qualitative research design to investigate the research questions. The intent of this qualitative research using a critical inquiry approach was to establish the perspective of those directly affected by procedures, policy, and diversity in a higher education setting. This critical inquiry was used to challenge, and analyzer; which aligns with the social, political, and cultural context (Merriam, 2009) of this study.

Often categorized as a lived experience is diversity; therefore, phenomenological research marks the essence of this philosophy (Creswell, 2009; Phillips, 2016). Phenomenological approach includes studying a small number of subjects to understand patterns and relationships of meaning (Creswell, 2009). Most importantly, using a phenomenological approach allows the researcher to evaluate one's own experiences to understand those that participated within the study (Creswell, 2009), as it coincides with one of the researcher being a person of color. Furthermore, the researchers conduct qualitative inquiry with the goal to obtain and acknowledge the human condition (Phillips, 2916) within a specific setting. Consequently, studying the behavior as it occurs naturally within a setting (Merriam, 2009) allowed for the natural progression of this study. Guided by the following research questions was this inquiry: How does cultural competency influence post-secondary learning environments as it relates to organizational value? How does critical race theory affect the embedded academia culture as it relates to organizational value? What policy or procedures are currently in place at higher education institutions to promote diversity and cultural competency and are they effective? 


\section{Method}

The qualitative data collected within this inquiry generated from one student focus group composed of five students of color $(\mathrm{N}=5)$, interviews with fifteen faculty $(\mathrm{N}=15)$, an open-ended online survey administered to two hundred students with a 50\% return rate $(\mathrm{N}=100)$, and document analysis. This myriad of data collection allowed for data validation through the collection of triangulated evidence. Creswell (2009), explained triangulation as providing a perspective from various individuals and methods of data collection. Prior to any data collection, signed informed consent forms acknowledged the study subjects' rights to participate voluntarily in the study, to withdraw from participation at any time, to ask questions, and to have confidentiality respected throughout the research project (Creswell, 2009). These consent forms met with the approval of the Human Subjects Review Committee of the University. The researchers conducted the interviews in the absence of any direct supervisors. Protected was the identity of the respondents using pseudonyms and the filtering of identifying information from the findings (Creswell, 2009).

\subsection{Focus Group}

Merriam (2009), described focus groups as a sample size of five to ten participants, while Krueger and Casey (2009) suggested focus groups are also typically composed of 5-10 people. The objective of the qualitative research process is to understand the meaning individuals associate to a particular problem (Creswell, 2009). Conducted was a purposeful sampling of participants was conducted to include those who are directly affected by the diversity process and the implementation of an inclusive setting. Purposeful sampling intends to provide a detailed account of the participants in the study and the important characteristics that they possess (Creswell, 2009). Selected were participants were selected based on their length of time within the University with all having spent four years attending and graduated from the University. The number of participants within the study was determined in process and associated to the point in which saturation or lack of new information occurs (Creswell, 2009). Five recently graduated students of color participated in the focus group. The demographics of the group was one transgender of mixed race (Hispanic and Black), two males, one mixed race (Asian and Black), the other Black, two females, one mixed race (Black and White), and the other lesbian and Black. The focus group took place in an environment conducive to an office setting and lasted an average of 60 minutes. The interview protocol was composed of 22 semi-structured questions that focused on the perceptions of the students' experiences at the University. The diverse backgrounds and genders allowed a perspective and voice that was reflective of the national demographic climate however interpreted from a university student viewpoint. The focus was "understanding how people interpret their experiences, how they construct their worlds, and what meaning they attribute to their experiences" (Merriam, 2009, p.5).

\subsection{Interviews}

Individual interviews occurred with 15 higher education faculty from the Midwest Research I University. The interviews utilized a semi-structured format (Merriam, 2009) allowing the researchers to interpret the interviewers' environmental perspective (Merriam). The interview protocol comprised of twenty-two questions that were consistent in wording and implementation (Merriam, 2009) with the focus group protocol but with a different perspective. The gender identity consisted of seven males, six females, and two gender-neutral participants. The racial makeup were six African Americans, one African, two Hispanics, and six Caucasians. Four of the participants were administrators because they could provide an overall perspective of the intent of diversity focus of the University and insights regarding student and faculty policy development, evaluation, and implementation. The remaining interviewees were faculty, who could provide information on diversity policies and insights regarding support or nonsupport an inclusive environment. The gained data outlined how the environment supported recruitment and retention of diverse faculty and how disseminated throughout the universities were the policies regarding organizational diversity values.

\subsection{Online Questionnaire}

Additionally, administered was an online open-ended questionnaire tool to a random clustered sample size of two hundred student participants that represented diversity within the setting. Of the distributed two hundred surveys, one hundred subjects responded. The participants' gender identity was $62 \%$ female and $38 \%$ male. The racial demographics were $49 \%$ people of color and $51 \%$ white. The education level included a combination of masters $(37 \%)$, bachelor (32\%), and undergraduate $(31 \%)$. The online questionnaire had 15 open-ended questions that focused on student's awareness of diversity policies that existed at the University and how those policies and procedures provided an inclusive environment for these students. According to Merriam (2009), validity is important and allows the researcher to draw solid conclusions from the instrument used to make inferences about the topic. To establish content validity the researchers designed the survey after a careful review 
of the constructs for this inquiry with a focus on diversity, cultural competencies, and critical race theory.

\subsection{Setting}

The setting for this inquiry is a Midwest Research I University. According to the Midwest Research I University (2016) data, the student body totalled 35,448. Relating to gender identity, females are $54 \%$ of the student population, with a minority population of 8,074 of the student community in 2015 (Midwest Research I University, 2016). Attributed to the recruitment approach for the university (Midwest Research I University, 2015 ) is the $22.78 \%$ representation of minority student enrollment. The faculty total included tenured, on tenure track, and non-tenured track was 1,973. Gender identity resulted in 59\% of women and $41 \%$ of men; however, men dominate administration roles at 64\%. The African American faculty included 55 individuals, which was 2.8\% of the faculty population.

\subsubsection{Data Analysis}

For this study, utilized were transcripts of focus groups and interviews, along with field notes in conjunction with the questions that guided the research (Creswell, 2009; Merriam, 2009). Data analysis including phases of coding: open, axial, and selective that concentrated on tagging the data, relating categories, and developing a proposition (Merriam, 2009). Axial coding is the process of grouping open codes (Merriam, 2009). Axial coding referred to as analytical coding, allowed the researcher to reflect and interpret meaning of the codes (Merriam). Axial coding was determined through reflection and interpretation of meaning (Merriam, 2009) by the researchers. This process allowed the researchers to obtain recurring patterns and regularities within the exploration of study (Creswell, 2009; Merriam, 2009). Additionally, interpretation of the open-ended survey data through the same process allowed for reoccurring themes, word repetition, and non-bias results. Finally, used was content analysis and analytic induction for document analysis (Merriam, 2009), allowing for simultaneous coding of data and categories that incorporate relevant information not only obtained through documentation but through focus groups and interviews allowing for triangulation (Creswell, 2009; Merriam).

\section{Results}

Below are the findings from the data analysis of the three research questions. Analyzed were qualitative data, along with documents from the institutions.

\section{Q1. How does cultural competency influence post-secondary learning environments as it relates to organizational value?}

Many faculty, students and leaders felt diversity had an impact on cultural competency within the university system. "When I think of cultural competencies I reflect of people from different backgrounds, I think of issues related to gender, race, ethnicity, culture, religion, sexual preferences. And so, I look at diversity as just people being and presenting who they are and feeling comfortable with being and doing."

One faculty member stated, "Cultural competency allows people of diverse backgrounds to achieve all they can be within the culture that they work or play in." A student voiced, "I would define diversity as fractures in homogeny, because a society that has a single unifying culture, regular ideas, no differences between people, that's not human." Another student noted, "Diversity comes when there is a majority and there are fractures of that, when there are differences, when other cultures are being introduced, when other ideas are being discussed amongst people. That's diversity, cultural competency, and inclusion."

Inclusivity also established a meaning within the research question voiced by a faculty member, "I would say making efforts to ensure that everyone has an opportunity to succeed in their setting. Another faculty member stated, "The University mirrors my definition, however, the action towards these efforts, are lacking. I feel like there's still a long way to go." A student mirrored this insight when noting, "As a minority I often feel that the value placed on diversity is not in the University's value system." Another student noted, "I have often felt left out."

Many participants expressed that being colorblind is not beneficial. A white, gender-neutral faculty member suggested, "Admittedly because of the way I was raised I used to think that, and in recent years I've come to realize that that does more harm than it does good." Another faculty member noted, "When you do that, you erase the experiences of people, it denies them that they have these experiences in the first place and that there is a problem. It's like while trying to do a good thing, you're erasing this huge problem."

An Administrator voiced, "I think the statement of colorblindness is well intended, but I don't agree with it, because I don't think that's giving diversity ... I think it's almost like saying it doesn't exist to me, when you say colorblind. I think diversity does exist, and what we have to do is embrace that and encourage it to reveal itself in 
different ways. Another administrator suggested, "That's what makes us who we are. I don't want to be colorblind, and say, "well, I'm going to treat everybody the same." The mere fact that somebody would say that tells me that they probably have a way to go."

Many students also agreed with faculty and administration, as one voiced, "When it comes to equal rights, yes. But different cultures should be respected and celebrated." While another noted, "I don't care if people say they are "color-blind", but I don't believe it unless that person is blind and deaf. One does notice skin color, eyes, accents, etc. whether "they" admit it or not." Still another student pointed out, "It's naive. People look different on the outside and that's ok..."

When recognized, cultural competency has an impact to the university setting. All participants felt that culture, diversity, and inclusion has a place in education with the understanding that it adds value to learning, professional and personal growth, and business strategies. Moreover, while policies and procedures were in place to enhance diversity the perceived issue is a common thread of the lack of leadership action, perhaps through the lack of cultural competency.. While many saw the value of diversity, others felt the action behind the well-intended policies was not enough.

\section{Q2 How does critical race theory affect the embedded academia culture as it relates to persistence to organizational value?}

The responses focused on the effects of stereotypes, trust, and societal issues. Most, administrators, students, and faculty noted they have been stereotyped, lost trust and felt the pressure of society, no matter their race. The consensus from majority of participants was society impacts the way people think, act, and effects the outcomes

For example, stereotypes effect trust and perception, as a faculty member expressed, "I applied for a position at the University. Looking at my name, you would think I would be a Caucasian woman. There was another person that was supposed to be interviewed with me her name was something different. It sounded like it was more ethnic than a Caucasian name. When it was time for me to have my interview, the person came out and asked for Katie. Instead of her standing in the general area, she walked towards the Caucasian lady thinking her name was Katie, it was not."

A student responded, "In the realm of academics, I was always asked by people (mostly white people) during introductory sentiments, if I played sports at the institution. As to say, that I can't be there simply for academic reasons and no other reason than sports." While another student noted, "It would be great not to be the only person of color in a class", and a faculty member of color noted, "Since I am the only person of color in my department I get assigned all search committees, as that token of diversity."

An administrator shed light on societal pressures and the impact to critical race theory, "It used to be that you would have things like the march that you talked about... There was the women's march, a week later, there was right to life marches, and you see all that happen, all sides of the spectrum. What I find extraordinarily interesting about that is then what? Nothing has happened. That's what frustrates people." A faculty member noted, "There was a day in this country where that demonstration, that outpouring of frustration or energy around an idea would move the needle, and in today's world is it does not move the needle. What it does, it has the opposite effect causing further division...."

Critical race theory, for the university participants, highlighted stereotypes and societal pressure. It highlighted how one can be discourage when treated a specific way or doing nothing when interpreting the minority voice. Again the opportunity lies, per the participants of the study, in actionable change.

\section{Q3. What policy or procedures are currently in place at higher education institutions to promote diversity} and cultural competency?

While the administrators are aware of policy, overall they felt a need for focusing on more inclusivity throughout the institution. As one administrator stated, "We developed a diversity plan, they talk about the number of minority students, retention, recruitment, and graduation. I think the structures and the policies are in place now, but the ability to enforce that is different." Another faculty member stated, "Yes there are support for the need for diverse student populations and faculty population, but often it seems those strategies are not changing anything regarding diversity."

Specifically, faculty did not acknowledge specific policy, but rather trainings and committees. Overall, faculty noted not effectively administered was policy. As one faculty member stated, "I know that we have to go through trainings every year. I also know that not everybody pays attention to the trainings. I feel like there could be more that could be done." Another faculty member noted, "Most of our trainings are online which does not allow for much self-reflection or critical discourse." 
Another faculty member expressed, "I think there's very little there. I think it all depends on your particular unit, your particular supervisor." As another noted, "As a system, as a whole, I think that they are doing some work in the issues related to culture, competency, culture, and diversity. The chancellor has a diversity committee; they have set measurements, outcomes and expectations..."

Students are primarily aware of events, clubs on campus, resources, and federally mandated diversity quotas (in their opinion) for the university. However, the student participants did not mention specific diversity policy. As a student stated, "I believe counselling is available..." Another student reported, "The Multicultural Office had programs and individuals that could help...tutors, academic counseling." Another student noted, "I have gotten most of my understanding about how to get help is there is a racial issue from other students, not form the faculty."

The data suggests communication, assessment, and implementation is a factor relating to policy at the University. While there may be diversity policy within the higher education system, many are unaware of the specifics of the policies. Rather they are more aware of events, programs, and projects about diversity.

\section{Discussion}

Many researchers attributed the disparity of color and gender identity to universities' leadership and diversity policy (Crownson, Mitchell, \& Shipps, 2011; Daun-Barnett, Moronski-Chapman, \& St. John, 2013). This inquiry also identified the lack of cultural competencies as a contributing factor to the disparity that existed at this University system, while highlighting the need for leaders who would take action such as disseminating diversity policies in a systematic way that goes beyond just token diversity training and events. All participants felt that a University who have diversity as an organizational value would do a more effective job of recruiting and retention of people of color in both the student and faculty population. Similarly, the participants' responses supported what other scholars (Coleman \& Pellitteri, 2013, Cross, 1989) have highlighted as the lack of fidelity in the implementation of cultural competencies throughout the organization. The participants discussed all three divisive cultural characteristics including cultural destructiveness, cultural incapacity, and cultural denial/indifference (Cross, 1989). . Furthermore, as seen through the lens of CRT (Parker \& Villalpando, 2007) identified by faculty and students of color was examples of exclusions. Furthermore, both the faculty and students noted the lack of communication and implementation of diversity procedures and policy. Therefore, while the administration has created diversity policy, the understanding and practice of cultural competencies appears not affected by said policy. As the Association of American Colleges and Universities, personnel (2015) argued the national, state, and regional shift in population and demographics may require an astute policy awareness for faculty and students of color that will close the gap of misrepresentation.

\section{Implications for Practice}

The 21 st century higher education system requires leadership to comprehend the value of cultural competencies, diverse inclusiveness, and the adaption of transformational behaviors for the survival of the institution. For a full representation of faculty of color, not only in the teaching ranks but also in administration, implementation of a focused approach to inclusion must occur. Policies and procedures throughout the Academy must reflect inclusivity. Furthermore, leadership must be resolve in this requisite to diminish the disparities among faculty and student populations, creating such populations that are representative of the total stated population Furthermore, the research revealed transformational leaders should embrace and encourage differences and demonstrate empathy. Likewise, a leader should be willing to be an open-minded change agent. This change agent should support the notion of actionable inclusivity, and trust within the higher education system to enhance organizational value. Needed is transformational leadership to enhance cultural competencies to alter the acceptance of inclusive structures or strategies within the setting and by doing so enhanced the capacity of a University to meet the ever-changing challenges of higher education for the 21 st century.

\section{References}

Association of American Colleges and Universities (2015). Step up \& lead for equality: What higher education can do to reverse our deepening divides? Washington, DC: Bill and Melinda Gates Foundation.

Bardach, E. (2012). A practical guide for policy analysis: The eightfold path to more effective problem solving. Los Angeles, CA: Sage Publications, Inc.

Brown-Glaude, W. R. (2009). Doing diversity in higher education: Faculty leaders share challenges and strategies. Piscataway, NJ: Rutgers University Press.

Coleman, D., \& Pellitteri, T. (2013, May 8). Cultural competency continuum. Retrieved from www.dialoguegroup.com 
Cottrill, K., Lopez, P., \& Hoffman, C. (2014). How authentic leadership and inclusion benefit organizations, Equality, Diversity, and Inclusion: An International Journal, 33(2), 275-292.

Creswell, J. W. (2009). Research design: Qualitative, quantitative, and mixed methods approaches ( ${ }^{\mathrm{rd}}$ ed.). Thousand Oaks, CA: Sage Publications, Inc.

Cross, T. L. (1989). Towards a culturally competent system of care. Washington, DC: Technical Assistance Center.

Crowson, R. L, Mitchell, D. E., \& Shipps, D. (2011). Shaping education policy: Power and process. New York, NY: Routledge.

Delgado, R., \& Stefancic, J. (2012). Critical race theory: An introduction ( $2^{\text {nd }}$ Ed.). New York, NY: NYU Press.

Dennison, P., Gosling, B. R., \& Marturano, J. (2003, June 1). A review of leadership theory and competency frameworks. Retrieved from www.leadership-studies.com.

Diller, J. V., \& Moule, J. (2005). Cultural competency: A primer for educator. Belmont, CA: Thomas/Wadsworth.

Flaherty, C. (2015). University of Missouri students call for black faculty target. Inside Higher Ed.

Gaetano, Y. D., \& Espana, C. (2010). Cultural competence in education. New York, NY: Center for Puerto Rican Studies Hunter College.

Gallegos, J. S., Gallegos, S. A., \& Tindall, C. (2008). The need for advancement in the conceptualization of cultural competence. Advances in social work, 9, 51-62.

Gooden, S. T., \& Norman-Major, K. A., (2012). Cultural competency for public administrators. New York, NY: Routledge.

Hiraldo, P. (2010). The role of critical race theory. The Vermont Connection, 31, 53-59.

Kouzes, J. M., \& Posner, B. Z. (2002) The Leadership Challenge Jossey-Bass, San Francisco, CA.

Krueger, R., \& Casey, A. (2009). Focus groups: A practical guide for applied research $\left(4^{\text {th }} \mathrm{ed}\right)$. Thousand Oakes, CA: Sage Publications, Inc.

Ladson-Billings, G. (2009). Just what is critical race theory and what is it doing in a nice field like education? In E. Taylor, D. Gillborn, \& G. Ladson-Billings (Eds.), Foundations of critical race theory in education (pp. 17-36). New York, NY: Routledge. https://doi.org/10.1080/095183998236863

Litowitz, D. E. (2009). Some critical thoughts on critical race theory. In E. Taylor. D. Gillborn, \& G. Ladson-Billings (Eds.), Foundations of critical race theory in education (pp. 291-310). New York, NY: Routledge.

Merriam, S. B. (2009). Qualitative research: A guide to design and implementation. San Francisco, CA: Jossey-Bass.

Northhouse, P. G. (2013). Leadership: Theory and practice (6 ${ }^{\text {th }}$ ed.). Thousand Oaks, CA: Sage.

Phillips, S. (2016). Brown is the new white: How the demographic revolution has created a new American majority. New York: The New Press.

The University of Missouri, C. (2013, February 12). Statistics and Demographics: Ethic/Racial Distribution Comparisons at MU. Retrieved from http://www.university.missouri.edu/about/stats

\section{Copyrights}

Copyright for this article is retained by the author(s), with first publication rights granted to the journal.

This is an open-access article distributed under the terms and conditions of the Creative Commons Attribution license (http://creativecommons.org/licenses/by/4.0/). 